\title{
ANALISIS INDEKS VEGETASI MENGGUNAKAN CITRA SATELIT FORMOSAT-2 DI DAERAH PERKOTAAN (Studi Kasus: Surabaya Timur)
}

\author{
Agneszia Anggi Ashazy, Agung Budi Cahyono \\ Program Studi Teknik Geomatika FTSP-ITS, Kampus ITS Sukolilo, Surabaya, 60111 \\ Email: agungbc@geodesy.its.ac.id
}

\begin{abstract}
Abstrak
Wilayah Surabaya Timur memiliki lahan konservasi, tambak, boezem, dan wilayah RTH berupa hutan mangrove yang cukup luas sehingga memiliki andil dalam kontribusi sebaran vegetasi kota Surabaya. Oleh karena itu, dibutuhkan pemantauan luasan vegetasi pada daerah tersebut.Dengan adanya teknologi penginderaan jauh, kini pengamatan wilayah perkotaan menggunakanketelitian spasial yang tinggi salah satunya adalah dengan satelit FORMOSAT2.Indeks vegetasi adalah suatu formulasi pengolahan data inderaja secara digital yang dapat diarahkan secara khusus untuk mengkaji informasi tematik dari lahan bervegetasi.

Hasil penelitian ini menunjukkan bahwa citra FORMOSAT-2dapat digunakan untukmenganalisa data indeks vegetasi dengan menggunakan algoritma NDVI,EVI2, dan SAVI. Indeks vegetasi SAVI menghasilkan keakurasian hubungan yang lebih baik dibandingkan metode NDVI dan EVI2 dimana koefisien determinasi dari metode SAVI adalah 0,9469. Luasan tutupan vegetasi sebesar 1276,86 ha atau $15,87 \%$ dari luas Surabaya Timur yang berarti hanya menyumbang $3,86 \%$ dari luas kota Surabaya. Sawah merupakan alokasi tutupan lahan yang paling luas memiliki repersentasi vegetasi dari luas wilayah Surabaya timur. Luas repersentasi vegetasi di wilayah Surabaya Timur yang paling dominan ada pada kisaran $25-50 \%$.
\end{abstract}

Kata Kunci: Surabaya Timur, Indeks Vegetasi, Citra FORMOSAT-2

\section{PENDAHULUAN}

Seiring dengan peningkatan jumlah penduduk yang menyebabkan semakin tingginya perubahan penggunaan lahan yang mengakibatkan berkurangnya jumlah tutupan lahan oleh vegetasi khususnya di daerah perkotaan, keadaan ini menyebabkan menurunnya kualitas lingkungan di daerah perkotaan (Dardak, 2006).

Wilayah Surabaya Timur tak luput dari perkembangan perkotaan, tetapi dapat disebut sebagai wilayah yang masih hijau karena fasilitas umum dalam hal ruang terbuka hijau banyak tersedia di wilayah ini.Penggunaan data satelit penginderaan jauh untuk sumberdaya telah banyak dimanfaatkan. Resolusi spasial yang tinggi dapat digunakan untuk pemantauan nilai indeks vegetasi asalkan citra tersebut memiliki kanalkanal yang dibutuhkan dalam algoritma perhitungan indeks vegetasi.Pemanfaatan citra satelit dengan resolusi spasial yang tinggi sangat diperlukan di daerah perkotaan yang mempunyai tingkat keragaman tutupan lahan yang heterogen (Liang, 2007).
Indeks vegetasi adalah suatu formulasi pengolahandata inderaja secara digital yang dapat diarahkan secara khusus untuk mengkajiinformasi tematik dari lahan bervegetasi (Carolita, 1995). Penelitian ini dilakukan dengan menggunakan citra FORMOSAT-2 dengan metode algoritma NDVI, EVI2, dan SAVI untuk pemetaan tutupan vegetasi, hasil metode tersebut diharapkan dapat membantu dalam tersedianya informasi mengenai presentase kerapatan vegetasi di wilayah Surabaya Timur serta dapat menjadi bahan pertimbangan untuk menentukan kebijakan pemerintah dalam mengelola lahan di wilayah tersebut.

\section{METODOLOGI PENELITIAN}

Penelitian ini dilakukan di kota Surabaya yang terletak pada $7^{0} 9^{\prime}-7^{0} 21^{\prime}$ Lintang Selatan (LS) dan $112^{0} 36^{\prime}-112^{0}$ 54' Bujur Timur (BT).Surabaya memiliki luas sebesar 33.048 ha. Dalam penelitian ini wilayah yang dianalisa adalah Surabaya Timur yang memiliki luas sebesar $10.150,89$ ha. 


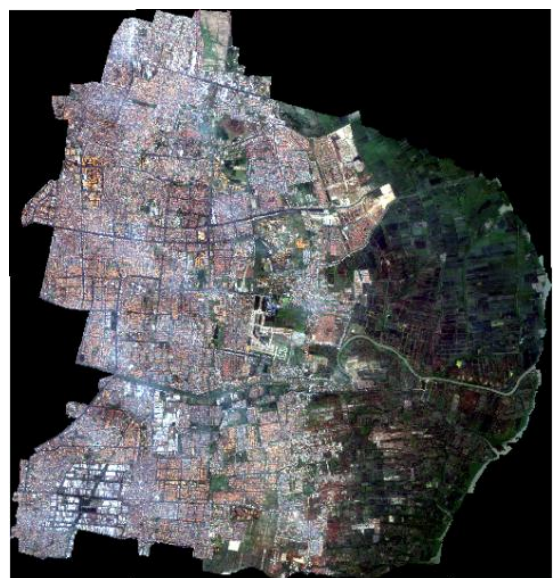

Gambar 1. Lokasi Penelitian

(Citra Formosat-2 wilayah Surabaya Timur)

Data yang digunakan dalam penelitian ini adalah Citra FORMOSAT-2akuisisi pada tanggal 4 Agustus 2008 yang diperoleh dari Jurusan Teknik Geomatika ITS. Peta Garis tahun 2002 diperoleh dari Dinas Cipta Karya Tata Kota Surabaya dan data groundtruth.

Perangkat lunak untuk analisis indeks vegetasi adalah Er Mapper 7.0 dan ENVI 4.6.1sedangkan untuk analisis repersentasi vegetasi menggunakan analysis tools pada Arc.Gis 10 sedangkan untuk analisis statistik menggunakan perangkat lunak Microsoft Excel 2003. Struktur data SIG yang digunakan adalah struktur data raster dengan pixel 8m.

Satelit FORMOSAT-2 yang diluncurkan pada bulan Mei 2004 adalah satelit penginderaan jauh pertama yang dikembangkan oleh National Space Organization (NSPO). sensor pada badan FORMOSAT-2termasuk instrumen penginderaan jauh dan Imager of Sprites and Upper Atmospheric Lightning (ISUAL).Berikut Tabel karakteristik sensor satelit FORMOSAT-2.

\section{Prosedur Penelitian}

Sebelum diolah dengan menggunakan algoritma indeks vegetasi, citra FORMOSAT-2 perlu melewati proses pembuatan jaring strenght of figure(SoF) dan koreksi geometrik menggunakan perangkat lunak ER Mapper 7.0
Tabel 1. Spesifikasi Citra FORMOSAT-2

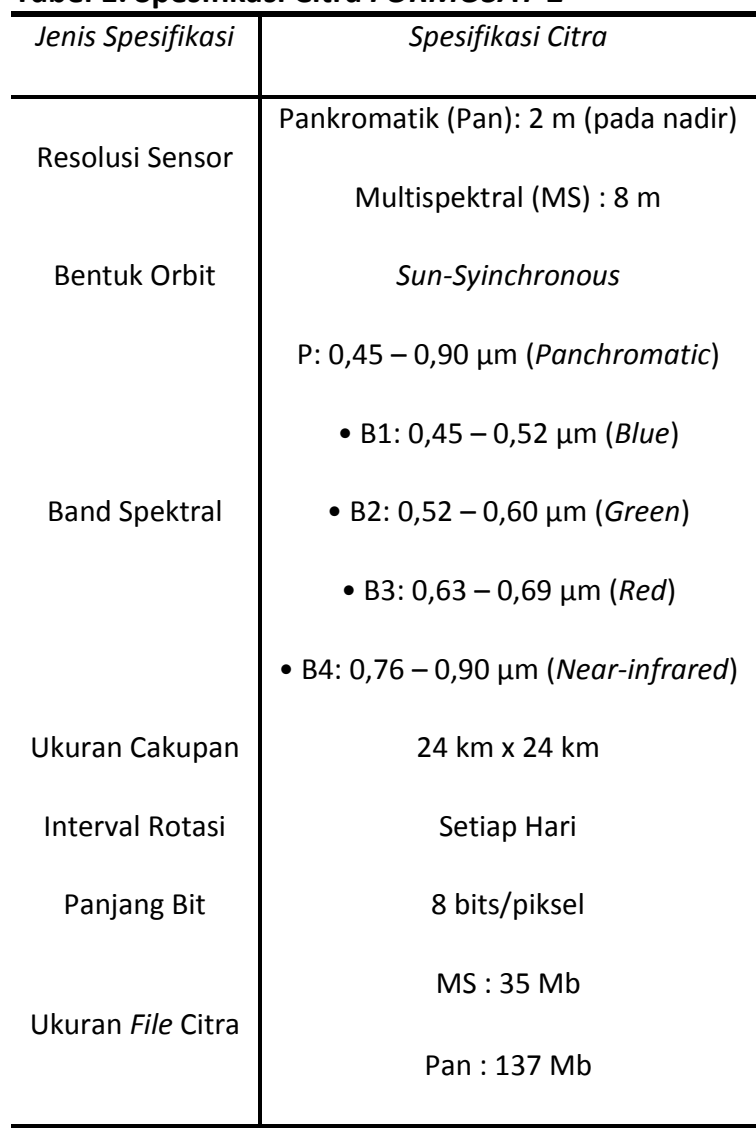

Nilai Strength of Figure yang memenuhi syarat adalah kurang dari 1 , artinya semakin kecil faktor bilangan Strength of Figure maka semakin baik pula konfigurasi jaringan dari jaring tersebut dan sebaliknya.

$$
\text { Strength of Figure }=\left[\operatorname{trace}\left(A^{T} A\right)^{-1}\right] / U
$$

Dimana:

U : Jumlah parameter yang dipengaruhi oleh jumlah titik kontrol yang digunakan.

Trace : Jumlah elemen diagonal dari suatu matrik.

Tabel 2. Hasil Koreksi Geometrik dan Perhitungan SoF

\begin{tabular}{l|c}
\hline Total RMS Error & 5,94 \\
Rata-rata RMS Error & 0,85 \\
SoF & 0,45 \\
\hline
\end{tabular}




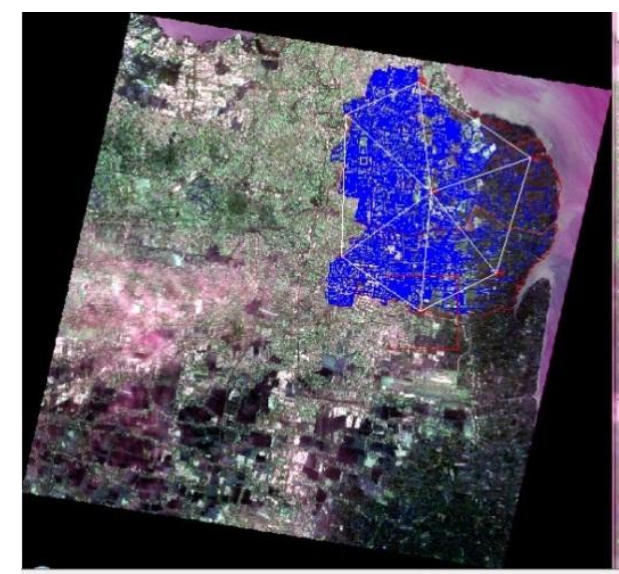

Gambar2. Sebaran Ground Control Point

Penelitian ini menggunakan 3 Indeks vegetasi yaitu NDVI (Normalized difference Vegetation Index),EVI2 (Enhanced Vegetation Index-2), dan SAVI (Soil Adjusted Vegetation Index). Berikut adalah algoritma ketiga indeks vegetasi tersebut:

$$
\begin{gathered}
N D V I=\frac{\text { Band } 2-\text { Band } 1}{\text { Band } 2+\text { Band } 1} \\
E V I 2=G * \frac{\text { Band } 2-\text { Band } 1}{\text { Band } 2+2,4 \text { Band } 1+1} \\
S A V I=\frac{(1+L)(\text { Band } 2-\text { Band } 1)}{\text { Band } 2+\text { Band } 1+L}
\end{gathered}
$$

Dimana :

Band 1 = band red

Band 2 = bandnear infra red

$\mathrm{G}=$ Gain Factor

L $\quad=$ =Faktor kalibrasi Tanah adalah 0.5 [4]

Sebelum Citra hasil indeks vegetasi dioverlaykan, dilakukan proses konversi data ke bentuk grid pada program ArcGis. Selanjutnya dilakukan proses overlay (spatial calculation) dan pembuatan layout peta. Lalu, dilakukan proses analisis regresi untuk mencari hubungan antara nilai indeks vegetasi dengan repersentasi vegetasi, nilai koefisien determinasi terbesar yang dihasilkan digunakan sebagai persamaan untuk menghasilkan peta sebaran vegetasi di wilayah Surabaya Timur.

\section{HASIL DAN PEMBAHASAN}

Pada bagian ini akan ditampilkan hasil dari pelaksanaan penelitian yang telah dilakukan mengenai Analisa indeks vegetasi dan peta repersentasi vegetasi Surabaya timur tahun 2008.

A. Analisa Indeks Vegetasi

Dari nilai indeks vegetasi dan repersentasi vegetasi dihasilkan persamaan regresi yang menunjukkan korelasi positif antara keduanya. Hal tersebut menunjukkan adanya hubungan antara nilai indeks vegetasi yang didapat dari citra FORMOSAT-2dengan repersentasi vegetasi.

Indeks Vegetasi SAVI menghasilkan keakurasian hubungan yang lebih baik dibandingkan metode NDVI dan EVI2 dimana koefisien determinasi dari metode SAVI adalah 0,9469 sedangkan NDVI adalah 0,9409 dan EVI2 adalah 0,9442.

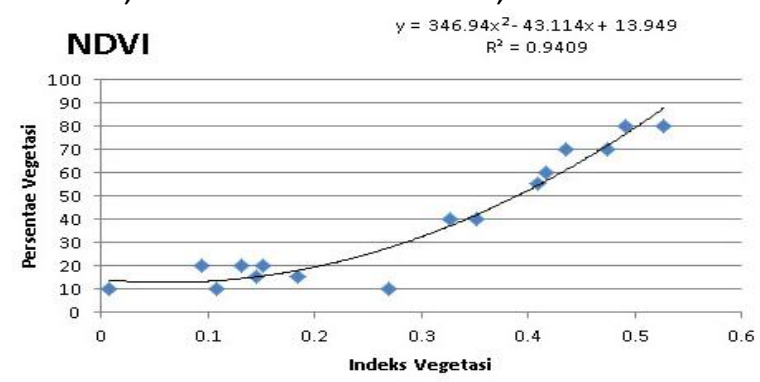

Gambar 3. Grafik Hubungan antara NDVI dengan repersentasi vegetasi

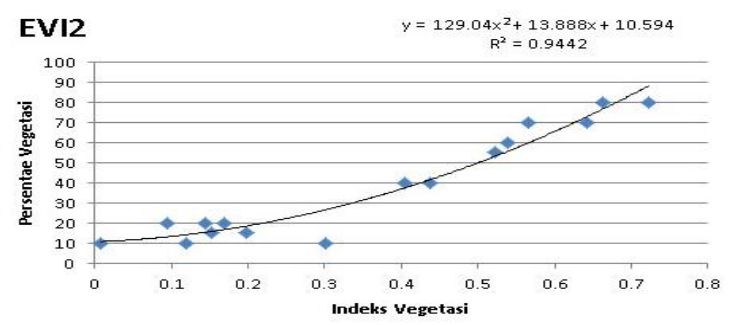

Gambar 4. Grafik Hubungan antara EVI-2 dengan repersentasi vegetasi 


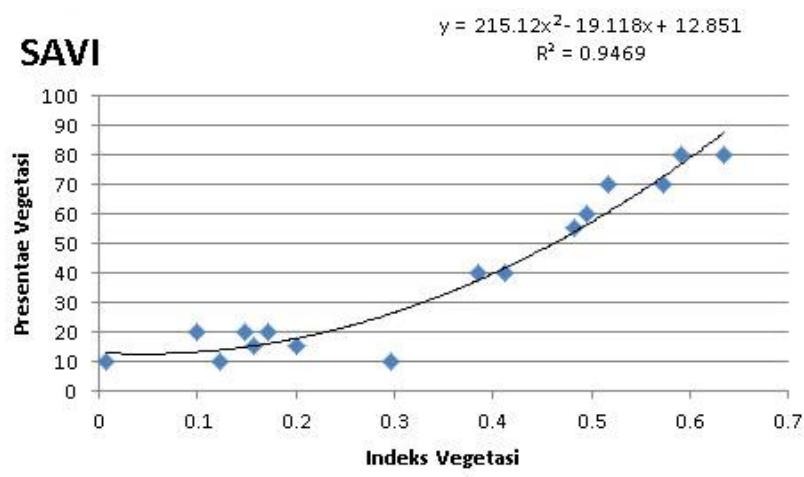

Gambar 5. Grafik Hubungan antara SAVI dengan repersentasi vegetasi

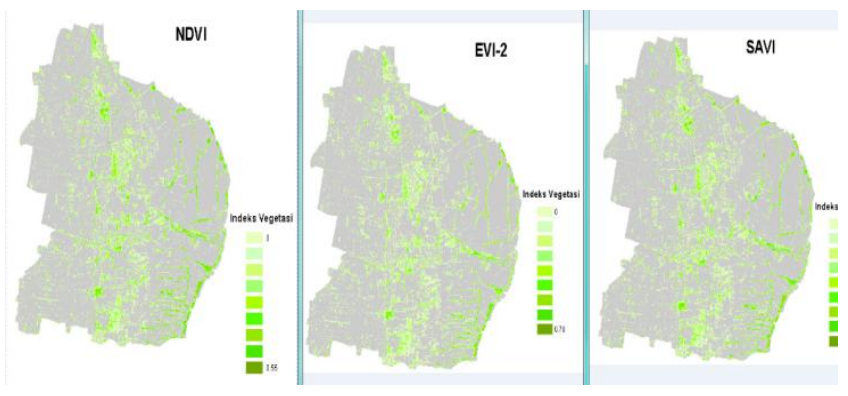

Gambar 6. Hubungan antara Indeks vegetasi dengan repersentasi vegetasi dengan NDVI(a), EVI2(b), dan SAVI(c)

Persamaan NDVI sangat cocok digunakan untuk daerah dengan vegetasi rapat sedangkan pada vegetasi jarang penggunaan persamaan SAVI sangat disarankan [5].Sehingga dapat menjadi acuan dalam penelitian ini yang menghasilkan koefisien determinasi tinggi pada persamaan
SAVI.Hal tersebut dikarenakan Surabaya Timur keberadaan vegetasi pada tiap tutupan lahan tidak begitu rapat, sehingga dapat mempengaruhi pantulan cahaya yang diterima oleh sensor.

B. Analisis Repersentasi Vegetasi Berdasarkan Peta Garis Surabaya Timur 2002

Untuk mendapatkan peta suatu sebaran repersentasi vegetasi maka digunakan persamaan yang diperoleh dari hubungan antara nilai indeks vegetasi dari SAVI dengan repersentasi vegetasi. Adapun Persamaan yang digunakan adalah:

Repersentasi vegetasi $=215,12(\text { SAVI })^{2}-19,118($ SAVI $)+12,851$

Dari peta garis Surabaya Timur 2002 dan hasil estimasi citra FORMOSAT-2dengan menggunakan analisa luasan pada Arc.Gis .10 didapatkan luasan tutupan vegetasi sebesar $1276,86 \mathrm{Ha}$ atau $15,87 \%$ dari luas wilayah Surabaya Timur. Dalam penelitian ini menunjukkan bahwa luas wilayah tutupan vegetasi di wilayah Surabaya Timur hanya menyumbang 3,86\% dari luas kota Surabaya. Sawah merupakan alokasi tutupan lahan yang paling luas memiliki repersentasi vegetasi yaitu $47,82 \%$ dari luas area tutupan lahannya sedangkan area terbangun merupakan daerah dengan tutupan vegetasi terendah yaitu 6,18\% dari luas area tutupan lahannya.

Tabel 3. Luas Area, Luas Tutupan Vegetasi, dan Repersentasi Vegetasi pada Tutupan Lahan

\begin{tabular}{ccccc}
\hline No. & Jenis Tutupan Lahan & Luas Area & Luas Tutupan Vegetasi & Repersentasi Tutupan Vegetasi (\%) \\
\hline 1 & Area Terbangun & 4195,18 & 259,11 & 6,17 \\
2 & Boezem & 1,57 & 0,61 & 39,27 \\
3 & Kuburan & 14,58 & 4,55 & 31,21 \\
4 & Lapangan & 15,72 & 6,23 & 39,62 \\
5 & Sawah & 620,70 & 296,87 & 47,82 \\
6 & Tambak & 2851,13 & 545,56 & 19,13 \\
7 & Vegetasi & 345,21 & 163,91 & 47,48 \\
& Total & 8044,11 & 1276,86 & 15,87 \\
\hline \hline
\end{tabular}


Tabel 4. Repersentasi Vegetasi untuk Tiap-Tiap Jenis Tutupan Lahan

Repersentasi vegetasi

\begin{tabular}{|c|c|c|c|c|c|c|c|c|}
\hline \multirow[t]{2}{*}{ Jenis Tutupan Lahan } & \multicolumn{2}{|c|}{$0-25 \%$} & \multicolumn{2}{|c|}{$25-50 \%$} & \multicolumn{2}{|c|}{$50-75 \%$} & \multicolumn{2}{|c|}{$75-100 \%$} \\
\hline & Luas (ha) & Persen & Luas (ha) & Persen & Luas (ha) & Persen & Luas (ha) & Persen \\
\hline Area Terbangun & 205,85 & 79,44 & 49,97 & 19,29 & 3,24 & 1,25 & 0,0544 & 0,0210 \\
\hline Boezem & 0,47 & 75,77 & 0,15 & 24,23 & - & - & - & - \\
\hline Kuburan & 3,59 & 78,83 & 0,94 & 20,59 & 0,03 & 0,59 & - & - \\
\hline Lapangan & 4,38 & 70,30 & 1,82 & 29,24 & 0,03 & 0,46 & - & - \\
\hline Sawah & 73,80 & 24,86 & 218,16 & 73,49 & 4,91 & 1,65 & - & - \\
\hline Tambak & 180,15 & 33,02 & 335,81 & 61,55 & 29,59 & 5,42 & 0,0068 & 0,0012 \\
\hline Vegetasi & 56,73 & 34,61 & 82,09 & 50,08 & 25,10 & 15,31 & - & - \\
\hline TOTAL & 524,97 & 41,11 & 688,94 & 53,96 & 62,88 & 4,92 & 0,0612 & 0,0048 \\
\hline Rata-rata Luas area & & 8,84 & & 11,60 & & 1,06 & & 0,0010 \\
\hline
\end{tabular}

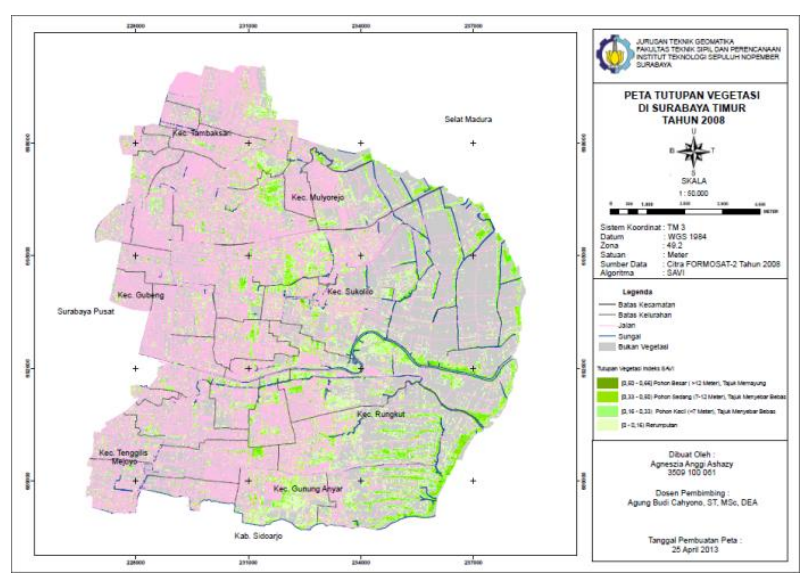

Gambar7. Peta tutupan Vegetasi Surabaya Timur Tahun 2008

Penelitian ini membagi 4 kategori repersentasi vegetasi berdasarkan repersentasi tutupannya yaitu repersentasi yang kurang dari $0-25 \%, 25-$ $50 \%, 50-75 \%$, dan repersentasi vegetasi yang lebih dari $75-100 \%$. $0-25 \%$ seluas $8,84 \%$ dari luas wilayah Surabaya Timur atau $41,11 \%$ dari luas area yang bervegetasi atau seluas 524,97 ha. Repersentasi vegetasi $50-75 \%$ mempunyai luas 62,88 ha atau $1,06 \%$ dari luas wilayah Surabaya Timur atau $4,92 \%$ dari luas area bervegetasi, sedangkan repersentasi vegetasi $75-100 \%$ hanya seluas 0,06 ha atau $0,001 \%$ dari luas wilayah
Surabaya Timur atau 0,005\% dari luas wilayah bervegetasi.

Area terbangun memiliki daerah dengan repersentasi vegetasi $75-100 \%$ dan $0-25 \%$ terluas yaitu 0.05ha dan 205,85ha, sedangkan untuk wilayah dengan repersentasi vegetasi $25-50 \%$ terluas yaitu sawah, untuk daerah $50-75 \%$ terluas didominasi oleh vegetasi.

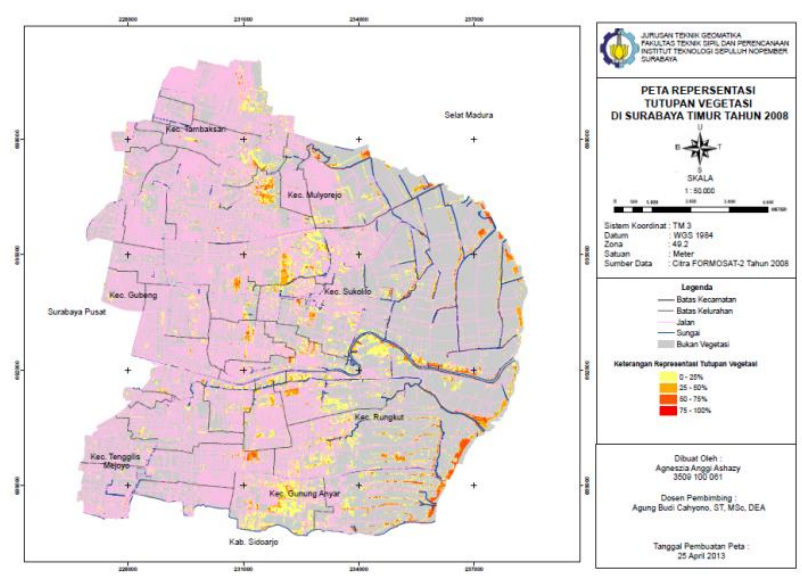

Gambar8. Peta Repersentasi Vegetasi Di Surabaya Timur Tahun 2008

Vegetasi sebagai pengendali tingkat pencemaraan udara perkotaan selain berperan sebagai penyedia oksigen dan penyerap karbondioksida, 
juga berperan sebagai pelindungterhadap asap dan gas beracun, serta penyaring udara kotor dan debu (Rahman, 2009). Maka dari itu pemilihan jenis tanaman sebagai pelindung di daerah perkotaan memiliki persyaratan tertentu agar ruang hijau disuatu kota dalam berfungsi maksimal.

Vegetasi di kawasan terbangun juga sangat dibutuhkan, selain untuk sirkulasi udara agar lebih segar, juga berfungsi sebagai peresap air masuk kedalam tanah selain itu juga vegetasi tersebut dapat memberikan kenyamanan berupa keindahan lingkungan yang dapat membuat efek psikologis masyarakat didaerah tersebut jauh lebih baik. Peran serta masyarakat dalam melestarikan lingkungan terutama menjaga kelestarian vegetasi didaerah perkotaan sangat dibutuhkan agar efek kebisingan perkotaan dapat diimbangi dengan baik.

\section{KESIMPULAN dan SARAN}

\section{Kesimpulan}

Dari penelitian ini dapat diambil beberapa kesimpulan, yaitu :

1. Citra FORMOSAT-2dapat digunakan dalam mendeteksi area bervegetasi didaerah perkotaan dengan menggunakan indeks vegetasi NDVI, EVI2, dan SAVI.

2. Persamaan repersentasi vegetasi $=215,12(\mathrm{SAVI})^{2}-19,118(\mathrm{SAVI})+12,851$ digunakan untuk mendapatkan peta sebaran presentase vegetasi karena memilikki nilai koefisien determinasi yang paling tinggi diantara indeks vegetasi lain.

1. Sawah merupakan alokasi tutupan lahan yang paling luas memiliki repersentasi vegetasi dari luas wilayah Surabaya Timur. Area terbangun memiliki daerah dengan repersentasi vegetasi $75-100 \%$ dan $0-25 \%$ terluas sedangkan untuk wilayah dengan repersentasi vegetasi $25-50 \%$ yaitu sawah, untuk daerah $50-75 \%$ didominasi dengan vegetasi.

\section{Saran}

Bagi Dinas Kebersihan dan Pertanaman kota :

1. Untuk pengembangan area bervegetasi, sebaiknya dipertimbangkan mengenai pemelihan jenis tanaman pada area hijau di
Surabaya sehingga mampu membantu memaksimalkan kerapatan vegetasi pada area tersebut.

2. Lebih dipertimbangkan lagi untuk pengembangan ruang terbuka hijau pada area terbangun yang masih sedikit jumlah ruang terbuka hijaunya.

\section{DAFTAR PUSTAKA}

Dardak, A.H. 2006. “Peran Penataan Ruang dalam mewujudkan Kota Berkelanjutan di Indonesia". Seminar Penataan Ruang Berbasis Apek Ekologis untuk Mewujudkan Kota Berkelanjutan, Jakarta.

Liang, S., T. Zheng, D. Wang, K. Wang, R. Liu, S. Tsay, S. Running, \& J. Townshend. 2007. “Mapping High-Resolution on Interpreting Tower-Based Flux Observations". Remote Sensing of environment, 112, 337-349.

Carolita, I., I Made P., Y. Erowati, dan Asikin A. 1995. Monitoring Keadaan Hutan dengan Menggunakan Data NOAA AVHRR di Daerah Kalimantan Barat dan Sebagian Kalimantan Timur. Warta LAPAN volume $43 \mathrm{Hal} 32-42$. Jakarta.

Jensen, J.R.2000. Remotesensing of the environmental Earth Resource Perspective. Prentice Hall, New Jersey-USA.

Ray, T.w.1995. A FAQ on Vegetation in Remote Sensing. Division of Geologicaland Planetary Sciences California Institute of Technology.California-USA

Rahman, A.A dan Sandi A.L.W. "Analisis Indeks Vegetasi Menggunakan Citra ALOS AVNIR-2 dan Sistem Informasi Geografi (SIG) untuk Evaluasi Tata Ruang Kota Denpasar". Jurnal Bumi Lestari, Volume 9 No. 1, Februari 2009, hlm. 1-11 